\title{
Concepções de leitura: diferentes perspectivas para a linguagem e o texto em sala de aula
}

\section{Resumo}

Fernanda Callefi Panichella*

Este artigo tem como proposta discutir e analisar textos relacionados às três concepções de leitura que Koch e Elias (2006) apresentam. Tomando como base o foco (i) no texto, (ii) no autor, (iii) na interação Também utilizaremos como aporte teórico as reflexões de Coracini $(1995,2005)$, que estão fundeadas em uma crítica aos modelos estruturalistas e interacionistas, com respaldo na perspectiva da Análise do Discurso de linha francesa a fim de mostrar que este modelo é bastante adequado no trabalho com práticas de leitura em sala de aula e será demonstrado uma atividade de leitura com base na Análise do Discurso.

Palavras-chave: Discurso, Leitura, Sala de aula.

\begin{abstract}
This article aims to discuss and analyze texts related to the three conceptions of reading Koch and Elias (2006) present. Based on the focus (i) the text; (ii) the author, (iii) the interaction will also use as the theoretical reflections of Coracini $(1995,2005)$, which are anchored in a critique of structuralist and interactionist models with support from the perspective of French Discourse Analysis in order to show that this model is well suited to work with reading practices in the classroom and will be shown a reading activity based on Discourse Analysis.
\end{abstract}

Keywords: Speech, Reading, Classroom

\section{Introdução}

Atualmente, reconhece-se a leitura também como atividade social, com evidência na presença do outro, daquele que é interlocutor do leitor. Assim, é possível postular que o significado não está nem no texto, nem no leitor, no entanto, nas convenções de interação social em que ocorre a leitura. Por isso, tem-se o intuito de discutir e exemplificar as três concepções de leitura (i) foco no texto, (ii) foco no autor, (iii) foco na interação texto-autor-leitor, com intuito de uma demonstrar uma outra proposta, no caso, a discursiva tendo em vista o sujeito e as condições de produção.

Coracini (2005) opõe-se a uma visão de sujeito uno, dono do seu dizer e com controle sobre sua significação, dessa forma, fazendo críticas às duas concepções de leitura: (i) a leitura como decodificação, refere-se à descoberta de um sentido, ainda está

Doutoranda Universidade Estadual de Maringá (UEM), Maringá - PR, Brasil, e-mail:

fcallefi@yahoo.com.

Revista Leitura V.2 no 56 - jul/dez 2015 - Número regular - Autor/a: Fernanda Callefi 
presente nas escolas; (ii) leitura como interação, tem-se a construção de um sentido, também está presente nas escolas e a priori no meio acadêmico. Assim, a autora apoia suas reflexões na Análise do discurso de linha francesa.

É necessário, segundo a autora, deslocar uma visão de linguagem em que os sujeitos determinam livremente os sentidos do texto ou ainda que o sentido venha determinado primeiramente pelo texto e pelo autor. Neste artigo, tem-se o intuito de encaminhar a compreensão de leitura, de um ponto de vista teórico e prático, o que exige um empenho de colocar visões em confronto e de tentar dar sentido às criticas que um modelo apresenta em relação ao outro. Serão abordadas as perspectivas do texto, do leitor e da interação do leitor-texto, com suas respectivas análises em textos escolares, e no final de cada concepção haverá um comentário, tendo em vista o ponto de vista discurso. Por fim, será demonstrado um exemplo de sequência didática a fím de demonstrar como poderia ser trabalhado um texto neste modelo teórico.

1. Perspectiva estruturalista: foco no texto

De acordo com Kato (1985) o texto como fonte única de sentido, possui uma visão estruturalista e mecanicista da linguagem. Nesta perspectiva teórica, o sentido estaria aprofundado às palavras e às frases, estando, assim, na dependência direta da forma. Tal modelo concebe a leitura como decodificação (modelo bottom-up), em que a leitura é vista como um processo instantâneo de decodificação de letras e sons. O sentido, deste modo, está arraigado às palavras e às frases, melhor dizendo, depende diretamente da forma. Neste caso, o percurso que faz a informação é ascendente, quer dizer, de baixo para cima, do texto para o leitor. Assim o texto ganha existência própria, independente do contexto e da situação comunicativa. Ou seja, o leitor apenas recebe o saber presente no texto. Além disso, é visto como produto acabado e lógico do pensamento do autor, entendida como processo de captação de ideias.

De acordo com Menegassi (2005, p. 18) a leitura, nesta concepção, é vista como um processo passivo de simples reconhecimento de palavras e ideias, em uma clara demonstração de capacidade de cópia de informações. Esse modelo supõe que o leitor parte dos níveis inferiores do texto para sucessivamente compor as diferentes unidades linguísticas e chagar aos níveis superiores do texto.

Doutoranda Universidade Estadual de Maringá (UEM), Maringá - PR, Brasil, e-mail: fcallefi@yahoo.com.

Revista Leitura V.2 no 56 - jul/dez 2015 - Número regular - Autor/a: Fernanda Callefi 
No estruturalismo, a leitura tem como base o texto de tal maneira que o leitor não recebe papel algum a desempenhar, a não ser o de decodificar. É previsto o uso indutivo e linear das informações. Neste âmbito, o leitor processa primeiramente seus elementos composicionais, seguindo um modelo hierárquico que obedece às sequências. A leitura passa a ser processada inicialmente pelas unidades menores, no caso, as letras e sílabas, para as partes mais amplas, como: palavras, textos. Desse modo, o leitor estabelece a relação das palavras decodificadas com os concernentes significados, e compreende o texto por meio da análise e da síntese.

Kato e Elias, por seu turno, tratam esta concepção de leitura como uma atividade de reconhecimento de sentido de palavras e estruturas, já que, o foco da leitura recai no texto. Muito comum, nesta teoria, exercícios que priorizam o vocabulário, na grande atenção do dicionário, com a busca por sinônimos. Fato ocorrido em diversos livros didáticos, quando o trabalho do vocabulário antecede o trabalho da interpretação ou em atividade de simples reconhecimento de unidades do texto, sem exigir empenho por parte do leitor, por exemplo, em atividades de preenchimento de lacunas. Fato que será visto no exemplo a seguir.

Os autores citados corroboram com a ideia de que o foco da leitura está voltado para o autor e suas intenções, de forma que o leitor desempenha um papel passivo no processo. Para reforçar Leffa (1996), retrata este modelo como uma metáfora, pois o texto seria um espelho com uma forma fixa, em que o sujeito é concebido como receptor passivo.

Segundo Menegassi (2005, p. 19) os processos ascendentes de leitura alicerçam os métodos de alfabetização que se preocupam com letras, sílabas, até chagar às palavras e só, dessa forma, poderão ser lidas, estão como proposta em muitas manuais didáticos, os quais solicitam respostas a um questionário identificadas no texto, por exemplo.

A seguir demonstraremos algumas atividades contidas em alguns livros didáticos a fim de exemplificar esta concepção estruturalista, tira I.

Leia a tira.

Doutoranda Universidade Estadual de Maringá (UEM), Maringá - PR, Brasil, e-mail: fcallefi@yahoo.com.

Revista Leitura V.2 no 56 - jul/dez 2015 - Número regular - Autor/a: Fernanda Callefi 

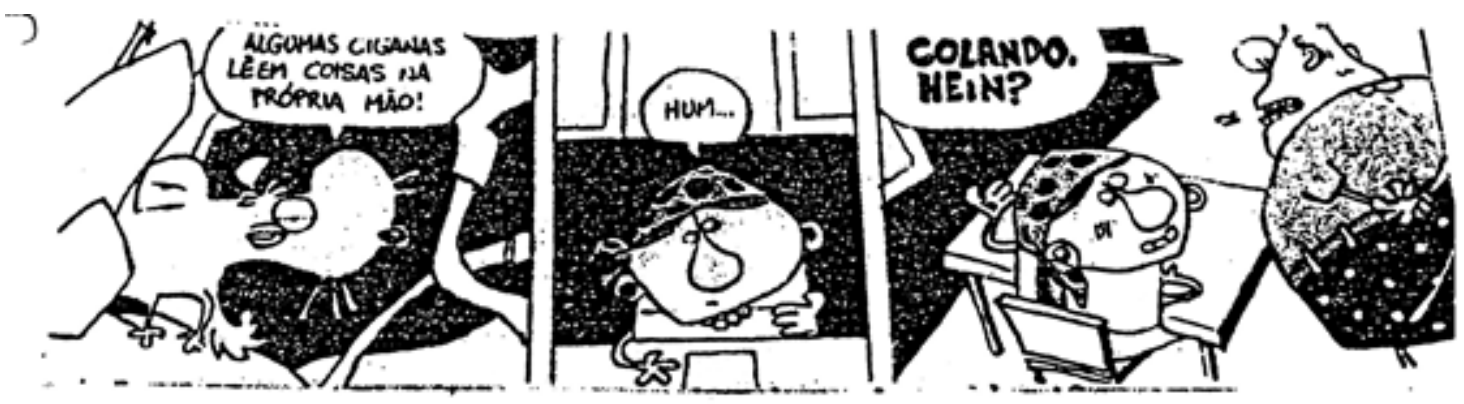

Atividades

a) O primeiro quadrinho apresenta três substantivos. Identifique-os.

b) É possível substituí-los por pronomes substantivos sem que haja prejuízo no sentido da tira?

(CABRAL, I, C. M. Palavra Aberta, $7^{\circ}$ série, p. 14)

Os exercícios da tira I se encaixam na concepção estruturalista, porque o texto utilizado poderia ser qualquer outro já que não está contextualizado diretamente com o exercício, conforme Travaglia (1996). Além do mais, não há outro objetivo além de oferecer os substantivos requisitados na primeira questão: "O primeiro quadrinho apresenta três substantivos. Identifique-os". O que evidencia apenas o ensino de gramática, desconsiderando a situação comunicativa e o indivíduo. Em segundo lugar, o exercício não se preocupa em solicitar as regras sobre o que são substantivos e em que momentos podem utilizá-los. Dessa forma, o estudo da gramática é seu único foco desconsiderando os outros estudos da língua.

A concepção de língua que subsidia as questões refere-se a uma visão de língua como estrutura de modo que a leitura é processada tendo em vista a palavras "encontre substantivos" e "substitua os pronomes substantivos", não dando possibilidade para que o leitor haja como sujeito ativo trazendo novos sentidos á tira ou as condições de produção deste texto. A leitura é processada das palavras (substantivos ou pronomes substantivos) para o texto. O aluno-leitor em contato com o texto terá de reconhecer as palavras sem se dar conta dos sentidos contidos na tira.

Neste caso, vale discutir a tira não somente trazer à tona uma concepção de gramática como mero exercício mecânico, como também a noção de texto e contexto de que o leitor deve reconhecer as palavras e dessa forma chegar ao sentido do texto, sem qualquer problematização ao contexto ou mesmo da dimensão social e histórica língua.

Doutoranda Universidade Estadual de Maringá (UEM), Maringá - PR, Brasil, e-mail: fcallefi@yahoo.com.

Revista Leitura V.2 no 56 - jul/dez 2015 - Número regular - Autor/a: Fernanda Callefi 
Embora seja um texto atual e adequado aos alunos de $7^{\circ}$ Ano, aborda acontecimentos cotidianos e apresenta, inclusive, uma gíria "colar", os exercícios se enquadram nesta concepção de linguagem, pois não conversa ou interage com o interlocutor, não discute sobre o texto, não propicia uma abertura para interpretações ou dúvidas sobre o que se pede. Ademais, o professor está como capataz do ensino, no qual ele apenas cobra (identifique e explique) sem aceitar reclamações e deseja que o texto seja compreendida sem problemas.

É bastante comum encontrar, nos livros didáticos, perguntas sobre o texto a partir das quais basta o aluno passar os olhos pelas superfícies linguística do texto e detectar partes que as palavras repitam na pergunta. O texto, visto como pretexto para uma abordagem mecânica língua, é, em diversos casos, alvo de identificação de estruturas formais da língua, fato que foi constado com o exemplo da tira.

De acordo com Coracini (1995, p. 14) a prática de leitura torna-se um exercício mecânico baseado na mera prática de diferenciar o significado literal em oposição ao metafórico, o denotativo em relação ao conotativo e ainda distinguir o objetivo o subjetivo. Além disso, nesta perspectiva, existe apenas uma leitura correta, sendo ela do professor ou até mesmo do livro didático. A atividade poderia ter partido do conhecimento prévio do aluno para se pensar, talvez, nas corrupções existentes no mundo a até mesmo no país, e que a "cola" estaria alicerceada entre uma dessas formas ilícitas. Tendo em vista as posições do aluno X professor ou mesmo cidadão X governo, por exemplo.

\subsection{Perspectiva cognitiva: foco no leitor}

A perspectiva teórica trará o leitor em primeiro plano, quer dizer, tem-se o lugar do processo top-down e o bottom-up sai de cena.

Este modelo teórico, descendente, tange a ideia de que o leitor não realiza uma leitura linear e decodificada, que não há um procedimento sequencial letra por letra, palavra por palavras, para obter uma leitura proficiente. O processo de leitura se dá do leitor para o texto, ou seja, de cima para baixo e não como foi visto no modelo ascendente. Dessa forma, o leitor é responsável pela construção do sentido, já que a leitura é permeada por seu conhecimento de mundo adquirido previamente, porque por meio desse conhecimento que ele atribui significado ao texto.

Doutoranda Universidade Estadual de Maringá (UEM), Maringá - PR, Brasil, e-mail: fcallefi@yahoo.com.

Revista Leitura V.2 no 56 - jul/dez 2015 - Número regular - Autor/a: Fernanda Callefi 
É importante salientar que diferentes pessoas lendo o mesmo texto apresentam variações no qual se refere à compreensão dos sentidos, pois dependerá dos seus propósitos, conhecimentos armazenados em sua memória, suas atitudes, esquemas conceptuais, a cultura social de cada indivíduo, entre outros, conforme Goodman (1987).

De acordo com Coracini (2010, p. 14), esta concepção é vista como interação entre os componentes do ato da comunicação escrita. O leitor é o portador de esquemas - mantais - socialmente adquiridos, aciona estes conhecimentos prévios e os confronta com os dados do texto, "produzindo", dessa forma, o sentido.

Segundo Goodman (1987, p. 17) para que seja possível a compreensão é necessário que o leitor inferencie, explicando melhor, "complemente a informação disponível utilizando o conhecimento de conceptual e linguístico e os esquemas que já possui". Os esquemas formam uma "rede de conhecimentos" que são armazenados de modo organizado na memória do leitor e que são acionados quando ele processa o texto.

Como pode ser verificado nesta tira II.
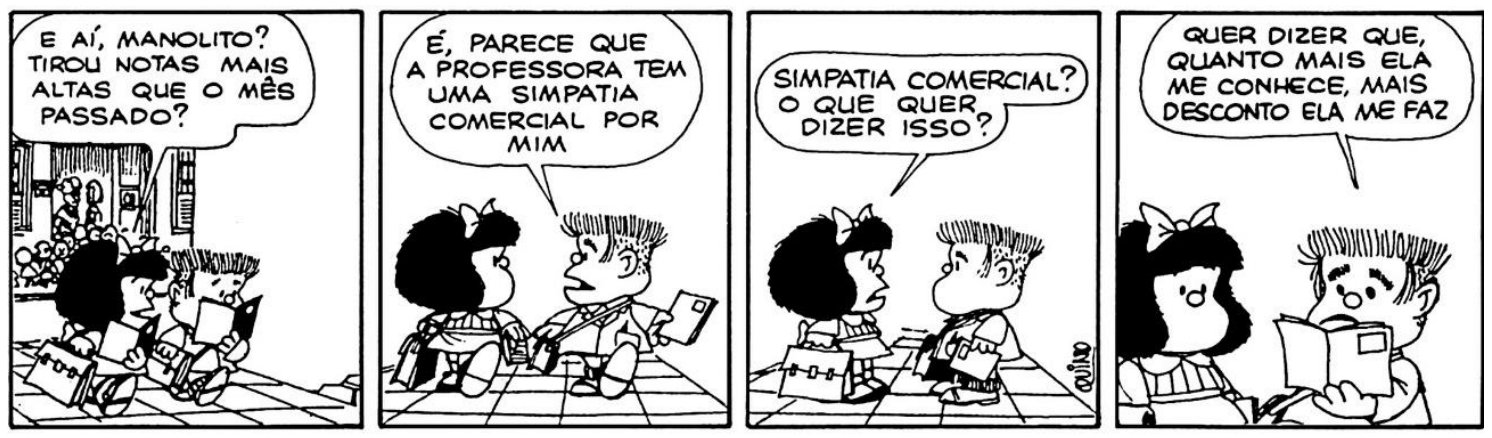

Atividades

a) O que Manolito quis dizer com "simpatia comercial"?

b) A que desconto Manolito se refere?

(Língua Portuguesa. Projeto Telares: sequência de aulas - 6ºno . Editora Ática, 2012)

Para responder à pergunta, nesta perspectiva, o leitor realiza inferências, complementando a informação disponível com seu conhecimento conceptual, linguístico e os esquemas que já possui. Dessa forma, o leitor aciona esquemas adquiridos por meio de experiências pessoais em relação ao comércio ou mesmo às

Doutoranda Universidade Estadual de Maringá (UEM), Maringá - PR, Brasil, e-mail: fcallefi@yahoo.com.

Revista Leitura V.2 no 56 - jul/dez 2015 - Número regular - Autor/a: Fernanda Callefi 
compras e estabelece sentidos para a tira. De tal modo, parte do conhecimento partilhado, de que, se o sujeito faz compras com frequência no mesmo lugar é possível que se ele torne cliente, e consequentemente, receberá descontos. O personagem da tira faz esta alusão ao comércio com a experiência que a professora tem com ele na sala de aula, ou seja, quanto mais ela o conhece, mais descontos de notas ela faz nas diferentes modalidades de avaliação.

$\mathrm{Na}$ tira apresenta a palavras "desconto", mas não diz a que se refere esta redução. Assim, o leitor tem papel altamente ativo no processo de instauração dos sentidos no texto, na medida em que ele faz previsões, confere e confirma hipóteses sobre o texto, por isso, o leitor consegue perceber que este desconto por estar relacionado ao ambiente escolar refere-se ao "desconto" de notas. De fato, se a compreensão do texto é realizada mediante de deduções e inferências do leitor segundo seus conhecimentos prévios e utilizando recursos para estabelecer antecipações, isto é, quanto maior o cabedal de informações um leitor ter a respeito do texto menor será a dependência dele para estabelecer a compreensão.

O sujeito é visto como ativo, pois cabe a ele "inferir", acionando esquemas e interagindo com outros textos. Antemão o texto é visto como o texto-produto trata-se de um conjunto de pegadas a serem utilizadas para recapitular as estratégias do autor e, por meio delas, será possível chegar aos objetivos do produtor do texto, segundo (KATO, 1985 p.57). Ainda segundo a autora

\footnotetext{
"a leitura não passa a ser vista como um processo que extrai o sentido final do texto, este é o elemento que delimita a gama de interpretações possíveis, algumas das quais pode não ter sido planejada pelo autor" (KATO, 1985).
}

Assim sendo, voltando na tira II, o aluno que talvez conheça uma professora que venda algum produto, poderia pensar que quanto mais ela o conheça mais teria "descontos" em relação aos valores, consequentemente, deixaria de lado o contexto escolar. Então, nesta concepção, o autor não consegue delimitar os possíveis sentidos do seu texto, porque dependerá das mais variadas interpretações. No caso, o bom leitor seria aquele que, diante do texto, conseguiria acionar os seus conhecimentos prévios sobre o que estaria relacionado ao "desconto" no contexto aluno e professor e dessa forma tivesse meios de confirma esta hipótese com dados do texto.

Doutoranda Universidade Estadual de Maringá (UEM), Maringá - PR, Brasil, e-mail: fcallefi@yahoo.com.

Revista Leitura V.2 no 56 - jul/dez 2015 - Número regular - Autor/a: Fernanda Callefi 
Nesta perspectiva intermediária, o bom leitor é aquele capaz de percorrer as marcas deixadas pelo autor até chegar à formulação de suas ideias ou possíveis intenções com aquele texto, pois mesmo que o texto seja um elemento importante para resgatar a leitura literal, o leitor que encontra indícios para significados não literais, conforme Kato (1985).

Baseado em Coracini (1995) este modelo entende a leitura como processo ativo de construção mental, por conseguinte, ler consiste em ativar pacotes de conhecimentos estruturados, acompanhados de instruções para o seu uso. A autora critica este modelo, pois representa um desejo de controle da construção do sentido por parte do sujeito, visto que, há um desejo de o sujeito ser fonte e origem do dizer. É importante salientar que este modelo de leitura é encontrado habitualmente no meio acadêmico.

\subsection{Perspectiva interacionista: foco no texto-autor-leitor}

Nesta concepção tanto o texto quanto o leitor são imprescindíveis para o processo da leitura. Então, para a produção de sentido é necessária a interação entre autor, texto e leitor. O significado não fica restrito nem no texto nem no leitor, porém na interação entre texto e leitor. Neste âmbito, o ato de ler passa a ser visto como um processo que integra tanto as informações contidas no texto quanto as informações que o leitor traz para o texto.

Segundo Koch e Elias.

\footnotetext{
...na concepção interacional (dialógica) a língua, os sujeitos são vistos como atore/construtores sociais, sujeitos ativos que dialogicamente se constroem e são construídos no texto considerando o próprio lugar da interação e da construção dos interlocutores (KOCH \& ELIAS, 2006, p. 10-11).
}

O leitor deve acionar os conhecimentos prévios, realizando estratégias de previsão e inferências constantes. Tendo como apoio as informações do texto e os conhecimentos adquiridos em sua vida, usando procedimentos que auxiliem no encontro de evidências das previsões e inferências realizadas.

A intencionalidade do autor é fundada pelas escolhas que o texto demonstra, pelas sinalizações, devendo o leitor detectar essas marcas textuais, mobilizando conhecimentos que construiu na sua história de sujeito e de sujeito-leitor. Neste âmbito,

Doutoranda Universidade Estadual de Maringá (UEM), Maringá - PR, Brasil, e-mail: fcallefi@yahoo.com.

Revista Leitura V.2 no 56 - jul/dez 2015 - Número regular - Autor/a: Fernanda Callefi 
o leitor reconstitui a intenção do autor pelas escolhas textuais, fato que não coincide essencialmente com o pensamento do autor.

Segundo Maurer (1988, p. 265) “a interdependência equilibrada entre informação contida no texto e os conhecimentos prévios do leitor é a condição essencial para a compreensão", ou seja, o leitor não pode se apoiar em apenas um dos níveis de informação, pois se o leitor se prender aos elementos textuais, poderá não perceber a mensagem no aspecto global. Em contra partida, se ignorar o texto e acreditar apenas nas suas hipóteses, predições, inferências, sem procurar confirmá-las no texto, poderá realizar uma interpretação tendenciosa. Por isso, o leitor deve utilizar a diferenciação como um processo de construção de pontes de sentido, de integração entre as fontes visuais proporcionadas pelo texto e pelo conhecimento do leitor.

Menegassi (2005, p. 32), por seu turno, ressalta que o leitor pode se aproximar das intenções do autor, atribuir possibilidades de intenções, todavia não chegar ao íntimo do autor.

É possível depreender a diversidade de leituras possíveis para um mesmo texto, pelo fato de que os leitores não são iguais, ou seja, cada indivíduo tem seu conhecimento de mundo. Diante disso, é possível asseverar que a leitura é um processo em que o leitor de acordo com os seus objetivos, conhecimento prévio sobre o assunto, interesses pessoas, realiza um trabalho ativo de compreensão e interpretação. Portanto, o processo de interação entre texto-leitor é um trabalho idiossincrático, próprio de cada leitor.

Leia a canção "A cor do homem".

\title{
A COR DO HOMEM
}

(Milton Nascimento e Fernando Brandt)

\author{
Mas como pode um homem \\ Escravizar outro homem? \\ O homem negro não é melhor \\ que o branco, nem pior \\ a pele branca não é pior \\ que a vermelha, nem melhor \\ a pele negra, branca, vermelha e amarela \\ é apenas a roupa que veste um homem \\ - animal nascido no amor \\ Criado para pensar, sonhar e fazer \\ Outros homens com amor.
}

Doutoranda Universidade Estadual de Maringá (UEM), Maringá - PR, Brasil, e-mail:

fcallefi@yahoo.com.

Revista Leitura V.2 no 56 - jul/dez 2015 - Número regular - Autor/a: Fernanda Callefi 
a- O que diferencia um homem do outro homem é a cor? Explique.

b- O que faz o preconceito racial ser tão forte até hoje?

Na letra da canção "A cor do homem" fala-se da pele negra, branca, vermelha, amarela". Todos são de cor. Há preconceitos marcantes em relação há quais cores? O que você pensa a respeito dessa discriminação?

c- O compositor Milton Nascimento tem pele negra, Fernando Brandt, pele branca. Juntos compuseram "A cor do homem". Um deles é melhor que o outro? Justifique.

d- Que outras formas de discriminação existem? Conte uma história em seu caderno na qual um personagem sofre discriminação de algum tipo. No mundo há muitos preconceitos. Há até preconceito linguístico. Mas saiba que é só uma questão de preconceito. Embora haja modos de falar que têm mais prestígio social, todos sabem a sua língua.

(PONTES, E. M. et al. Linguagem e interação. Curitiba: Módulo, 1996)

Neste caso as atividades de leitura se pautam na premissa que o texto, pelo fato de ser produto da interação, vai derivar na leitura de leitores distintos, isto é, cada leitor realizará uma leitura diferente do texto, pois a abordagem do texto se altera de individuo para indivíduo, como também os conhecimentos prévios. Assim, é possível imaginar a leitura como um processo idiossincrático.

Nesta abordagem, vale ressaltar que a leitura específica desta canção envolve a história do leitor e também os conhecimentos antepassados sobre a escravidão, a identidade do sujeito em relação como concebe a diferença socialmente. O leitor por meio das questões pode expor seus pensamentos e conhecimentos sobre os assuntos em pauta, se o que diferencia uma pessoa da outra é a cor de pele, ou mesmo o porquê ainda há preconceito, também compara os compositores da canção questionando se um é melhor do que o outro e por fim quer que o sujeito exponha outras formas de discriminação na qual ele poderá expor até mesmo uma experiência pessoal, em que poderá abordar outros tipos de preconceito, por exemplo, as diferentes variedades linguísticas.

$\mathrm{Na}$ questão "d" o aluno que tenha sofrido algum tipo de preconceito terá uma versão um pouco diferente em comparação com aquele que talvez só tenha ouvido falar sobre o assunto, pois não se sentiu marginalizado ou excluído, assim, apenas teve conhecimento de experiências alheias. De fato, segundo Koch e Elias (2006, p. 11) "a leitura é uma atividade na qual se leva em conta as experiências e os conhecimentos do leitor", episódio que pode ser comprovado com a canção e com as questões referentes ao texto. Há diferentes possibilidades de leitura, porque as experiências e as visões nunca são iguais ou homogêneas.

Doutoranda Universidade Estadual de Maringá (UEM), Maringá - PR, Brasil, e-mail: fcallefi@yahoo.com.

Revista Leitura V.2 no 56 - jul/dez 2015 - Número regular - Autor/a: Fernanda Callefi 
Segundo Geraldi (1997), essa abordagem de ensino permite lugar para a interação humana, considerando os contextos sócio-históricos e ideológicos. Visto que o produtor se torna um sujeito que pratica ações com a linguagem, melhor dizendo, produz ações que requerem atitude responsiva dos interlocutores, sujeitos interagem com o produtor.

A partir destas atividades foi possível detectar um leitor ativo, que colabora com a produção de sentido no texto, cabendo a ele inferir, acionar esquemas cognitivos e interagir com os dados do texto. Portanto, o bom leitor, nesta perspectiva, é aquele que é capaz de percorrer as marcas consentidas pelo autor para chagar à formulação de suas ideias e intenções.

Conforme Coracini (2005, p. 20), o modelo interacionista, acredita que há uma essência no texto, escondido, destarte, cabe ao leitor à tarefa de buscar ou capturar este sentido "oculto".

\subsection{Perspectiva discursiva}

Na perspectiva discursiva, não se lê um texto como texto, porém como discurso, isto é, levando-se em consideração às condições de produção.

Neste modelo de leitura é necessário considerar que o sujeito de linguagem retoma sentidos preexistentes e sua interpretação não é livre, como também não pode ser qualquer uma. Além disso, a leitura está conectada às determinações sócio-históricas do dizer. Ainda, o sujeito por ser falado pelo inconsciente, não tem controle total do que diz, assim sendo, aquilo que é dito não possui um significado único, pois depende dos diferentes significados e as condições de produção do discurso. Assim, as palavras mudam de sentido conforme as posições daquele que as empregam.

De acordo com Coracini (1995), baseando-se em Pêcheux (1990) é imprescindível levar em conta as duas ilusões das quais o autor fala e que constitui o sujeito como social e ideologicamente construído. A primeira ilusão ou esquecimento refere-se ao esquecimento ou ilusão de o sujeito ser fonte e origem do dizer quando na realidade retoma sentidos preexistentes, assim, a leitura passa a ser vista como centrada no texto, consequentemente, é vista como produto acabado e fechado. Fato que, nos preceitos discursivos, é necessário se fixar às relações de sentidos que se estabelecem Doutoranda Universidade Estadual de Maringá (UEM), Maringá - PR, Brasil, e-mail: fcallefi@yahoo.com.

Revista Leitura V.2 no 56 - jul/dez 2015 - Número regular - Autor/a: Fernanda Callefi 
entre o texto e outros. Já a segunda ilusão ou esquecimento é de existir apenas um sentido único. No entanto, no âmbito do discurso, ler compreender que tanto o sentido pode ser outro quanto o sujeito não possui controle pleno dos sentidos. Essa é uma ilusão necessária para que o sujeito se constitua em sujeito (ORLANDI, 2001).

Segundo Menegassi (2005, p. 35) texto e discurso não se confundem, pois discurso apresenta-se como efeitos de sentidos entre os locutores ou um processo de significação em que estão atualizados na língua, a história e o sujeito, interpelado pela ideologia a sociedade. Já o texto organiza a discursividade, por conseguinte, deve ser visto a relação com outros textos, com os sujeitos, com as circunstâncias de enunciação com a exterioridade, com a memória do dizer (ORLANDI, 2001).

De acordo com a autora, na prática de leitura é necessário considerar alguns questionamentos de ordem discursiva como: 1) os sentidos têm sua história, baseado nas condições de existência (produção) da linguagem; 2) um texto possui relação com outros discursos, 3) o sentido não está no texto, no entanto, na relação autor e leitor; 4) a interpretação depende da história de leitura, da compreensibilidade de quem lê; 5) sujeito e sentido são determinados histórico e ideologicamente.

Ainda conforme Orlandi (1983) a leitura é produzida em determinadas condições de produção imediatas e sócio-históricas, e propõe considerá-la como o momento crítico de constituição do texto, o momento no qual os interlocutores desencadeiam o processo de significação. De acordo com a visão discursiva, segundo a autora, todo texto é resultado de uma variedade de textos e se constrói perante determinadas condições de produção. Diante disso é importante destacar algumas características em relação às condições de produção: a) Os participantes na interação linguística - autor e leitor -, considerados como sujeitos determinados social e ideologicamente. b) $\mathrm{O}$ objeto discursivo. c) Tanto o objeto discursivo como os participantes na interação linguística funcionam por meio de formações imaginárias, explicando melhor, são representados, no texto, os lugares que os interlocutores conferem a si mesmo e aos outros.

Sobre as condições de produção de acordo com Coracini (2005, p. 27)

[...] não vemos ou não lemos o que queremos (de forma independente) qualquer momento, ou em qualquer lugar, assim como não podemos dizer ou fazer o que quisermos em qualquer lugar e a qualquer momento que autorizam a produção de certos sentidos e não de outros.

Doutoranda Universidade Estadual de Maringá (UEM), Maringá - PR, Brasil, e-mail: fcallefi@yahoo.com.

Revista Leitura V.2 no 56 - jul/dez 2015 - Número regular - Autor/a: Fernanda Callefi 
As condições de produção são acionadas pela memória discursiva que, quer dizer, o eixo da constituição dos sentidos. As palavras chegam até o falante repletas de sentidos, pois existe sempre um discurso anterior, que é exterior a quem e enuncia e que sustenta o que é dizível.

O interdiscurso ou a memória é, um conjunto de formulações feitas e esquecidas que, acaba determinando o que dizemos, assim, o falante retoma nas palavras aquilo que pertence ao já-dito, não obstante ignore sua existência, repete discursos que já não são mais inéditos, entretanto, essa repetição é capaz de produzir o novo, o deslize ou o deslocamento de sentidos, conforme Orlandi (2000, p.31).

De acordo com Orlandi (1988, p. 9) todo texto possui inscrito um leitor virtual, que é aquele constituído no próprio ato de escrita. Nesse âmbito, o leitor imaginário seria aquele para o qual o autor (destina) seu texto e para quem ele dirige. As informações imaginárias designam a) a imagem que o locutor tem de si mesmo; b) a imagem que o locutor tem de seu interlocutor; c) a imagem que o locutor julga que o interlocutor tenha do locutor; e) a imagem que o locutor faz do seu referente. Ainda segunda a autora, por meio das imagens, o sujeito-leitor projeta-se no lugar de seu interlocutor e, dessa forma, orientado pelo mecanismo da antecipação, constitui na textualidade um leitor virtual.

Há também um leitor real, aquele que lê o texto, assim, tem-se um leitor constituído com o qual ele tem de se relacionar. No processo de leitura ocorre a relação entre o leitor virtual e o real. Dessa forma, o leitor não interage com o texto - interação sujeito/objeto -, todavia, com outro(s) sujeito(s). No entender de Coracini (1995), são sempre construções, produto da interpretação de um dado leitor em um dado momento e lugar. $\mathrm{O}$ autor é considerado como princípio de agrupamento do discurso, como unidade e origem de suas significações, como suporte dessa coerência.

Os sentidos, para o modelo discursivo, são efeitos que se produzem sob determinações históricas, assim sendo é imprescindível questionar quais são as condições para que algo seja dito de uma determinada maneira para determinado(s) interlocutor(es) em determinado contexto sócio-histórico.

Neste modelo teórico, o sujeito da linguagem retoma sentidos preexistentes e sua interpretação não é livre, pois a leitura está atrelada às determinações sócio-históricas

Doutoranda Universidade Estadual de Maringá (UEM), Maringá - PR, Brasil, e-mail: fcallefi@yahoo.com.

Revista Leitura V.2 no 56 - jul/dez 2015 - Número regular - Autor/a: Fernanda Callefi 
do dizer. Aliás, o sujeito não tem controle do que diz, pelo fato de que aquilo que é dito possui mais de um significado.

Observe as propagandas e as questões que servirão como proposta para alunos da $1^{\circ}$ Série do Ensino Médio.

É importante lembrar que o professor antes de iniciar esta proposta deverá direcionar a aula com perguntas de pré-leitura questionando:

1) Vocês sabem de alguma obra governamental que já iniciou a mais de um ano e não foi concretizada? Comente sua resposta.

2) Os estádios brasileiros que foram construídos para a Copa de 2014 já foram concretizados em $2015 ?$

Explique.

I

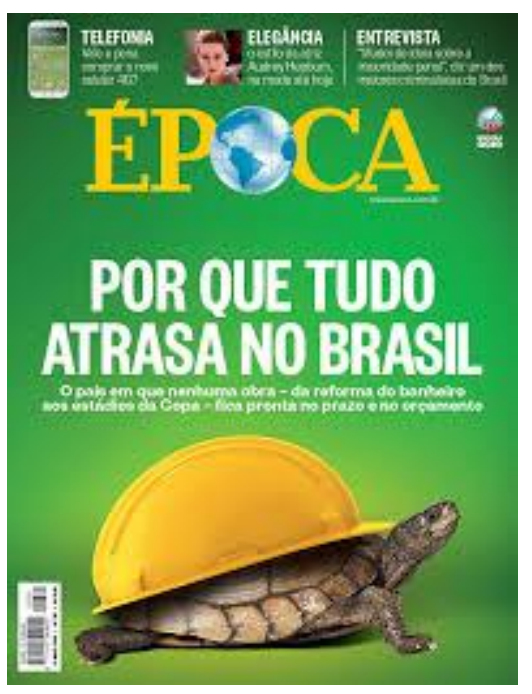

II

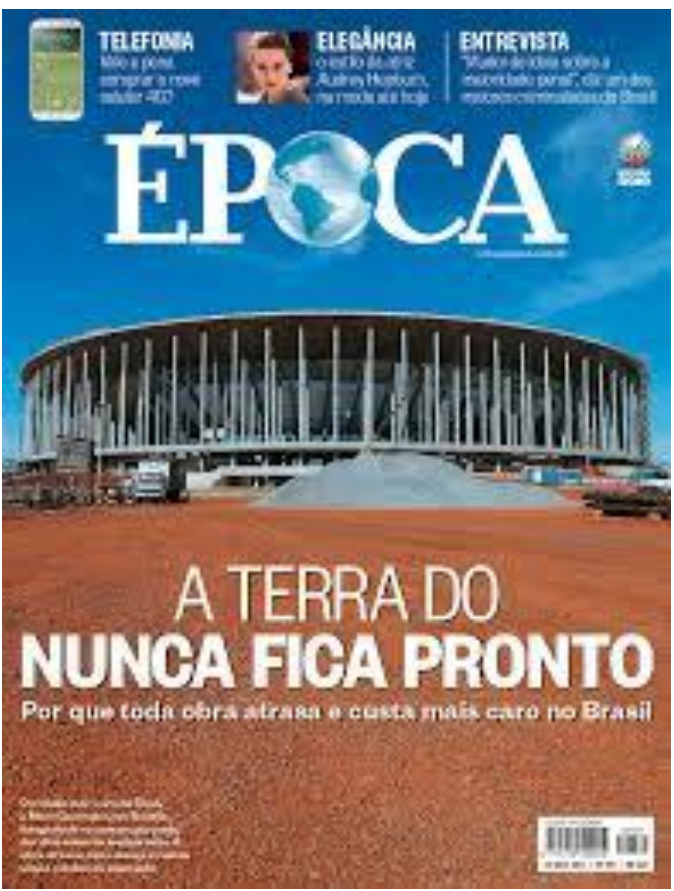

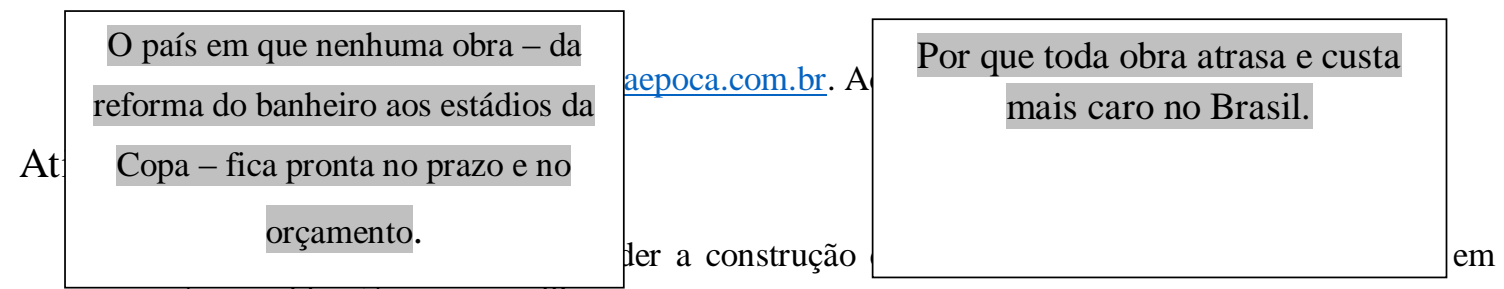

V1sta a problematica nacional?

b) Relacione os sentidos proporcionados por meio das cores da propaganda um com as cores da propaganda dois.

c) A que condições de produção ou lembranças imediatas as capas da Revista Época fazem referência?

Doutoranda Universidade Estadual de Maringá (UEM), Maringá - PR, Brasil, e-mail: fcallefi@yahoo.com.

Revista Leitura V.2 no 56 - jul/dez 2015 - Número regular - Autor/a: Fernanda Callefi 
d) Explique a intertextualidade, possível memória de outro texto, da segunda propaganda da Revista Época.

e) Como repercutiu para o povo brasileiro o não término dos estádios durante o período da Copa de 2014 ?

f) Além dos estádios quais são as outras obras começaram, há algum tempo, que ainda não terminaram e este fato já não é mais comentado pela mídia?

g) Como deveriam ser conduzidas essas questões de obras em um país, ou seja, deveria ter um prazo determinado e/ou um valor estimado? Explique.

h) Como a população poderia proceder para que não houvesse este tipo de problema no país, a não concretização das obras?

i) Quais são as palavras que poderiam substituir "A terra do" da segunda propaganda. Explique por que você utilizaria essas possibilidades neste contexto.

j) Como as perguntas indiretas auxiliam no sentido das propagandas.

A partir destas capas das Revistas Época é possível trabalhar as questões de memória discursiva, identidade do povo brasileiro e as intertextualidades que auxiliam na demonstração da identidade do sujeito. No caso, detectar o momento presente do dizer e observar o já-dito, quer dizer, entre constituição do sujeito e sua formulação.

Na primeira capa de revista é possível detectar que houve atrasado nos estádios da Copa, sem contar que o trecho "nenhuma obra fica pronta... no prazo e no orçamento" resgatam na memória do sujeito outras obras que vinham sendo construídos no país e que também ainda não estão acabadas, além disso, os valores finais dessas obras passam a ser bem maiores do que foi previsto na perspectiva inicial. Ou seja, o brasileiro tem que ficar esperando a construção das obras e ainda pagar por um valor maior do que o aquele estipulado. Por isso, na capa da revista há uma tartaruga, animal que caracteriza lentidão, também há as cores presentes na bandeira do Brasil, verde e amarelo. $\mathrm{Na}$ oração "Por que tudo atrasa no Brasil" é uma interrogativa indireta, pois se espera que o leitor real imagine, por meio de seus conhecimentos prévios, o que esta "pergunta" poderia estar afirmando.

As capas das Revistas discursiviza sobre a importância dada pela mídia, no ano da Copa 2014, em que se iniciou a Copa e mais uma vez o Brasil não tinha uma obra concretizada, no prazo determinado e com o valor previsto no orçamento. $\mathrm{O}$ atraso dos estádios passou a ser o ponto inicial para criticar outros não feitos prometidos e não cumpridos pelo governo PT. Então é possível, em sala de aula, visualizar as questões de condição de produção quando se tem a construção dos estádios e as cores da bandeira do Brasil, que está se referindo a Copa de 2014 e que mais uma obra não foi concretizada. Também é possível mostrar aos alunos como a mídia é efêmera, pois estes

Doutoranda Universidade Estadual de Maringá (UEM), Maringá - PR, Brasil, e-mail:

fcallefi@yahoo.com.

Revista Leitura V.2 no 56 - jul/dez 2015 - Número regular - Autor/a: Fernanda Callefi 
assuntos sobre os estádios e as obras não concretizadas já não são mais tão abordados pela mídia. E, infelizmente, acabam sendo esquecidos e pouco cobrados.

Já na segunda capa da Revista Época, tem essa mesma relação estabelecida com a primeira capa com o título "Por que a terra do nunca fica pronta" novamente uma oração interrogativa indireta, para que o leitor analise de acordo com seus conhecimentos e mais uma vez uma critica as obras que não são finalizadas e com custos exacerbados o que pode ser detectado em: "Por que toda obra atrasa e custa mais caro no Brasil". É interessante observar o texto não verbal, que traz uma obra incompleta, no caso, um estádio e na frente só o terreno sem construções. Também no título há a intertextualidade "A terra do nunca", que algo nunca se concretiza ou ainda quando ressalta "A terra do" poderia ser completado por brasileiros, pois depois muda a fonte da letra "nunca fica pronta" ou ainda de acordo com a memória discursiva do leitor ele poderia inferir que a terra de "ninguém" nunca fica pronta. Os governantes fazem o que acham convenientes como se não tivesse alguém que estivesse aprovando ou desaprovando essas ações. Junto com a não concretização dos estádios estão as escolas, hospitais, postos de saúde, contornos, projetos sociais, sistema hídrico eficiente, entre outros.

Também é importante considerar o leitor imaginário nos trabalhos com os alunos, fazendo-os perceber "como" e não "o quê" significa. Por exemplo: qual é a imagem de leitor tencionada na revista; qual é a imagem que a revista faz de si; qual a imagem a cerca do assunto que se constrói.

Contudo, é possível perceber que neste modelo de leitura o sentido é determinado pelo momento sócio-histórico, pela formação discursiva do leitor e pelo autor. Ademais, o sentido não pode ser controlado e depende das condições de produção de cada texto e das histórias de leitura do falante.

\section{Considerações Finais}

Diante das concepções de leitura é possível perceber que a discursiva de acordo com a posição do sujeito é possível estabelecer diferentes efeitos de sentido para determinadas formações discursivas podendo gerar interpretações diferenciadas de acordo com o interlocutor, logo é possível obter mais de uma interpretação de acordo

Doutoranda Universidade Estadual de Maringá (UEM), Maringá - PR, Brasil, e-mail: fcallefi@yahoo.com.

Revista Leitura V.2 no 56 - jul/dez 2015 - Número regular - Autor/a: Fernanda Callefi 
com as condições de produção e os aspectos sócio-históricos do falante, pois toda leitura tem uma história e todo leitor tem a sua história.

O professor deve possibilitar que os alunos participem dos sentidos dos textos e não que o docente ou mesmo o livro didático sejam condutores únicos da aula. Até por que não há uma interpretação única, mas sim, diferentes leituras de um mesmo texto. Além disso, deve mostrar que os sentidos não estão presos nas palavras e que se devem considerar outros elementos que possibilitam uma interpretação mais proficiente.

É possível perceber, que as reflexões e as análises realizadas, que toda leitura envolve uma produção; tanto "os ditos" como os não-ditos fazem parte do texto, então cabe o leitor saber ler e significar para dessa forma perceber a incompletude do texto e desfazer os efeitos de transparência; o leitor deve identificar as estratégias de manipulação inseridas no texto, o que torna o indivíduo ativo, uma vez que ele pode perceber a ideologia presente no texto e, assim, posicionar-se diante do texto.

\section{Referências}

CORACINI. MJ (org.) O jogo discursivo em sala de aula: um jogo de ilusões. Campinas: Pontes, 1995.

Concepções de leitura na (pós) modernidade. In: LIMA, Regina Célia de C. P. (Org.) da Boa Vista, São Paulo: Unifeob, 2005.

O jogo discursivo na aula de leitura: língua materna e língua estrangeira. SSão Paulo: Pontos Editores, 2010,

KOCH \& ELIAS, V M. Ler e compreender: os sentidos do texto. São Paulo: Contexto, 2006.

GERALDI, João Wanderley. Portos de Passagem. São Paulo: Martins Fontes, 1997.

GOODMAN, K. S. O processo da leitura: considerações a respeito das línguas e do desenvolvimento. In: FERREIRO, E; PALACIO, M. G. (Org.) Os processos de leitura e escrita: novas perspectivas. Porto Alegre: Artes Médicas, 1987.

KATO, Mary. No mundo da escrita: uma perspectiva psicolingüística. 7ed. São Paulo, Ática: 1985.

No mundo da escrita: uma perspectiva sociolinguística. São Paulo: Ática, 1986. LEFFA, J. Aspectos da leitura: uma perspectiva psicolinguística. Porto Alegre: 1996. MAURER, J. L. Compreencao de linguagem escrita: aspectos do papel do leitor. In: BOHN, H. I.; VANDRESEN, P. (Org.). Tópicos da linguística aplicada. Florianópolis: Ed. UFSC, 1988.

MENEGASSI, R. J. (Org.). Leitura e ensino: conceitos de leitura. Maringá: EDUEM, 2005.

ORLANDI, E. P. As histórias de leitura e suas condições. Leitura: teórica e Prática, Campinas, 1983.

Discurso e leitura. São Paulo: Cortez, 1988.

Doutoranda Universidade Estadual de Maringá (UEM), Maringá - PR, Brasil, e-mail:

fcallefi@yahoo.com.

Revista Leitura V.2 no 56 - jul/dez 2015 - Número regular - Autor/a: Fernanda Callefi

Panichella - p. 42 - 59. 
Análise de discurso: princípios de procedimentos. Campinas: Pontes, 2000.

2001.

Discurso e texto: formulação e circulação dos sentidos. Campinas: Pontes,

TRAVAGLIS, L. C. Gramática e interação - uma postura para o ensino de gramática no $1^{\circ}$ e $2^{\circ}$ grau. São Paula: Cortez, 1996.

Doutoranda Universidade Estadual de Maringá (UEM), Maringá - PR, Brasil, e-mail: fcallefi@yahoo.com.

Revista Leitura V.2 no 56 - jul/dez 2015 - Número regular - Autor/a: Fernanda Callefi Panichella - p. 42 - 59. 